\title{
Adsorption properties of iodine on fused silica surfaces when evaporated from tellurium in various atmospheres
}

\author{
Erik Karlsson $^{1,2} \cdot$ Jörg Neuhausen ${ }^{1}\left[\right.$ [ $\cdot$ Robert Eichler $^{1,2} \cdot$ Alexander Vögele $^{1} \cdot$ Andreas Türler $^{2}$
}

Received: 9 June 2020 / Published online: 28 August 2020

(c) The Author(s) 2020

\begin{abstract}
The evaporation of iodine containing species from tellurium has been investigated together with their adsorption behavior on a fused silica surface. In inert gas, the formation of two species was observed with adsorption enthalpies of around - 90 to -100 and -110 to $-120 \mathrm{~kJ} / \mathrm{mol}$, respectively. For reducing environments, a single species identified as monatomic iodine was observed with an adsorption enthalpy around $-95 \mathrm{~kJ} / \mathrm{mol}$. In oxidizing conditions, species with low adsorption enthalpies ranging from -65 to $-80 \mathrm{~kJ} / \mathrm{mol}$ were observed. Presumably, these are iodine oxides as well as oxo-acids of iodine $\left(\mathrm{HIO}_{x}\right)$. The results of the thermochromatography experiments performed here prove the usefulness of the employed production method for carrier-free iodine isotopes and enhance the understanding of the evaporation and deposition behavior of iodine under various chemical conditions.
\end{abstract}

Keywords Iodine $\cdot$ Tellurium $\cdot$ Thermochromatography $\cdot$ Fused silica $\cdot$ Adsorption

\section{Introduction}

With upwards of 450 currently operating nuclear power reactors worldwide, the waste problem is becoming an increasing worry. One of the possible ways to deal with this problem efficiently is introducing a nuclear reactor concept that is capable of treating the spent nuclear fuel through transmutation to reduce the required storage time. Such reactors require different components compared to light-water reactors, such as a coolant that is adapted for fast neutrons to facilitate transmutation. To achieve the goal of efficient transmutation of nuclear fuel on a large scale, research is proceeding in several projects, one of them being the MYRRHA-reactor [1]. The MYRRHA-reactor is a lead-bismuth eutectic (LBE) cooled fast neutron spectrum reactor constructed as a research and training facility as a well as a proof of concept. Novel reactor systems require licensing procedures to be performed, which include a thorough look at the chemistry of potential radiological hazards. One of these

Jörg Neuhausen

joerg.neuhausen@psi.ch

1 Laboratory of Radiochemistry, Paul Scherrer Institut (PSI), Forschungsstrasse 111, 5232 Villigen, Switzerland

2 Department of Chemistry and Biochemistry, University of Bern, Freiestrasse 3, 3012 Bern, Switzerland most prominent radiological hazards are iodine isotopes produced through fission. The behavior of these radionuclides have been extensively studied in classic light-water reactor systems. However, the adsorption behavior in a lead-bismuth based system is so far unexplored. Studies have been performed on the evaporation of iodine from a dilute solution in $\mathrm{LBE}$ in an inert $\left(\mathrm{Ar} / 5 \% \mathrm{H}_{2}\right)$ atmosphere. One of the studies found significant volatilization occurring around $800 \mathrm{~K}$ in an inert atmosphere $\left(\mathrm{Ar} / 5 \% \mathrm{H}_{2}\right)$ [2], however another found release temperatures around $700 \mathrm{~K}$ [3]. The maximum coolant temperature of the MYRRHA is $723 \mathrm{~K}$ [4], so fractional evaporation of iodine is expected which merits studying it in more detail. Apart from the evaporation of iodine from the LBE also the adsorption of the evaporated iodine species on surfaces is relevant for safety studies. To learn more about the adsorption behavior of the LBE/iodine system in different gas atmospheres $\left(\mathrm{H}_{2}, \mathrm{He}, \mathrm{O}_{2}\right)$, the mixing of LBE with natural tellurium followed by neutron irradiation to produce iodine is considered as a sample production route. The reason for this approach is the requirement of very small mole fractions of iodine present in the final sample, preventing simply mixing weighable amounts of iodine with LBE. To be able to properly assess the adsorption interaction of iodine it cannot be present in amounts that allow for more than a monolayer adsorbed to the surface [5]. 
The main concern with this approach is the introduction of significant amounts of tellurium ( $2 \%$ by weight) into the system which may influence the behavior of the iodine. To establish a baseline before attempting to interpret the behavior of iodine in an LBE system, experiments using irradiated natural tellurium were conducted. In some experiments, a pre-separation was performed where the iodine was evaporated onto a piece of silver foil prior to the experiment to examine the influence of the removal of a large fraction of the tellurium from the final sample. Previous similar studies have been performed successfully on $\alpha$-irradiated natural tin with tellurium being the desired end product as an analogue for polonium [6].

The binary tellurium-iodine system is not particularly well-studied chemically, especially at very low mole fractions of iodine. There are phase diagrams available, however these are not applicable at the mole fractions we are interested in $\left(x_{I} \sim 10^{-10}\right)$ [7]. Compounds that contain more than one iodine atom per molecule such as $\mathrm{TeI}_{4}$ and $\mathrm{TeI}_{2}$ are unlikely to form at these low concentrations. On the other hand, polyatomic compounds with respect to tellurium can form due to the abundance of tellurium in the system. The compounds identified as possible to form at these mole fractions are sparsely studied as single gaseous molecules and are instead often studied in the solid phase [8].

The fused silica surface was chosen for the adsorption experiments in the present study due to the large body of knowledge available, its simple stable chemical constitution, as well as existing correlations relating the sublimation enthalpy ( $\left.\Delta H_{\text {subl }}\right)$ of a macroscopic species to the microscopic adsorption enthalpy ( $\left.\Delta H_{\text {ads }}\right)$ of single molecules or atoms of the species on quartz [9]. Other experiments on the adsorption of iodine on fused silica generated via a fission source show a clear increased volatility in the presence of oxygen suggesting formation of volatile oxygen containing compounds of iodine [10].

The method used in this work to determine the affinity between a specific surface/gaseous chemical species pair is known as thermochromatography (TC). This method is based on the successive adsorption/de-adsorption equilibria established between gaseous chemical species transported in a carrier gas stream and a surface exposed to a negative temperature gradient. The species is evaporated and carried inside an empty, usually cylindrical column made of the investigated stationary surface material. During the transport, the gaseous species interacts with the surface numerous times, adsorbing to it and desorbing after a certain time. After a sufficient number of reversible interactions at equilibrium, thermochemical assessments can be made on the strength of the interaction based on the formation of characteristic deposition patterns on the surface known as internal thermochromatograms.

\section{Experimental}

\section{Sample preparation}

The sample preparation consisted of the irradiation of natural tellurium (Sigma Aldrich, Batch: MKBW7373V, $99.999 \%$, granules, $5-25 \mathrm{mg}$ ) by thermalized neutrons from the spallation neutron source SINQ for $3 \mathrm{~h}$ at a thermal neutron flux of $10^{13} \mathrm{n} \mathrm{s}^{-1} \mathrm{~cm}^{-2}$. This irradiation produced initial activity levels of approximately $3 \mathrm{kBq}$ of ${ }^{131} \mathrm{I}$ per $\mathrm{mg} \mathrm{Te}$, measured by a HPGe (High-purity germanium) $\gamma$-detector on the $364.5 \mathrm{keV} \gamma$-line [11]. The sample was placed in a stainless steel (SS316L) boat of approximately $15 \mathrm{~mm}$ in length and $3 \mathrm{~mm}$ in width. To capture aerosols potentially released from the sample, a piece of quartz wool was placed immediately downstream of the sample.

\section{Thermochromatography}

The equipment used for this series of experiments consisted of two furnaces, one to be used with water saturated carrier gas and the other to be used for experiments with low levels of moisture. Inside the furnaces there is an Inconel ${ }^{\circledR}$ tube in which the TC column is inserted. At one end of this Inconel ${ }^{\circledR}$ tube, the system for feeding gas through the furnace is connected. This system consists of a tube ending in a hollow metallic pin. At the end of the tube a mass flow controller is attached to control the flow velocity of the carrier gas. The chromatography columns used for these experiments consist of fused silica with a length of approximately $1200 \mathrm{~mm}$ and an inner diameter of $5 \mathrm{~mm}$ (Schmizo AG, Oftringen, Switzerland). The hollow metallic pin used as a gas inlet has an outside diameter of roughly $4 \mathrm{~mm}$. To close the gap between pin and column, Teflon tape was applied to the outside of the pin until it fits tightly into the fused silica column.

For the experiments performed in dry conditions a gas loop was used to clean the gas prior to the experiment. This gas loop features a Sicapent ${ }^{\circledR}$ moisture absorber and a hot $\left(900{ }^{\circ} \mathrm{C}\right)$ tantalum $\mathrm{O}_{2}$-getter as well as a dew point meter (Michell Easidew) to monitor the moisture content of the gas. Prior to the experiment, the gas in the system is pumped around the gas loop through the cold furnace until the conditions are satisfactory $\left(<100\right.$ vol ppm $\left.\mathrm{H}_{2} \mathrm{O}\right)$. Before an experiment is started, the thermal gradient furnace is turned on to allow it to stabilize its temperature profile reproducibly throughout the length of the stationary column. For water saturated conditions the difference is the lack of the gas loop and the addition of a water bubbler to saturate the gas with $\mathrm{H}_{2} \mathrm{O}$ at room temperature. The saturation concentration of $\mathrm{H}_{2} \mathrm{O}$ in the different gases at room temperature corresponds 
to about 2 vol\%, however when measuring the concentration using a dew point meter available after experiments were finished, the actual value in the gas was found to be closer to $1 \mathrm{vol} \%$ indicating incomplete saturation. Other differences between the two setups include differing ways of starting the experiment. In the setup with water saturated carrier gases, a pin is used to push the sample into the hot zone of the furnace to commence the evaporation. For dry conditions a starting furnace operating at $700{ }^{\circ} \mathrm{C}$ is used, which is separate from the gradient furnace. The experiment time was two hours in water saturated conditions and three hours in dry conditions.

Carrier gases used for these experiments were $\mathrm{H}_{2}, \mathrm{He}$ and $\mathrm{O}_{2}$ with flowrates of $25 \mathrm{ml} \mathrm{min}^{-1}$ for $\mathrm{O}_{2}, 28 \mathrm{ml} \mathrm{min}^{-1}$ for $\mathrm{H}_{2}$ and $45 \mathrm{ml} \mathrm{min}^{-1}$ for $\mathrm{He}$ for dry carrier gases. In water saturated conditions the flowrate was $25 \mathrm{ml} \mathrm{min}{ }^{-1}$ for all gases. The flowrates were verified using a mini-BUCK Calibrator M-5 from A.P. Buck Inc. At the exit of the Inconel ${ }^{\circledR}$ tube for both setups, a charcoal filter was fitted to capture any species of iodine with a low enough affinity to allow escape from the column. Each of the gradient furnaces was operated at a maximum temperature of $700{ }^{\circ} \mathrm{C}$, tapering off to room temperature at the end of the column. Sketches of the two setups used are displayed in Fig. 1.

After completing the experiment, the furnace was turned off along with the gas flow and allowed to cool down before the column was removed. The column is then measured in $1 \mathrm{~cm}$ steps on an HPGe-detector through a lead collimator with a small hole in it, enabling measurement of the column step-wise centimeter by centimeter. This produces a deposition pattern which describes the amount of activity present at each centimeter of the column. This pattern is then fed as experimental data into the Monte Carlo routine described below.

Additional experiments were conducted using iodine preseparated from the Te-source to examine how a reduction of the tellurium content in the system influenced the speciation. To produce samples for these experiments, the irradiated Te-samples were processed in the temperature gradient similar to the experiments described above, with the difference being a strip of silver foil added at a spot in the gradient furnace where a temperature of $150{ }^{\circ} \mathrm{C}$ was measured. This temperature was chosen to enable the majority of the iodine to be carried to the foil and adsorbed onto it strongly while minimizing the amount of tellurium present on it. In TC experiments metallic tellurium adsorbs to fused silica at around $400{ }^{\circ} \mathrm{C}$, and it deposits at even higher temperatures when using macroscopic amounts [6, 9, 12, 13]. Small pieces of the silver foil were then cut to produce samples to be used in further experiments.

\section{Monte Carlo simulations}

The Monte Carlo method utilized to describe this adsorption chromatography process is based on the model drawn up by Zvara [5]. The method takes into account experimental parameters such as for example carrier gas flowrate, thermal gradient, experimental time, and column dimensions. Additional parameters considered are the lattice vibrational spectrum of the surface in question as well as the adsorption enthalpy. The adsorption enthalpy is fed to the simulation as a variable parameter. From the initial guess, the adsorption enthalpy is adjusted until the deposition pattern produced by the Monte Carlo simulation agrees with the experimentally measured one. The goodness of fit was judged by visual comparison of the simulation result with the experimental data. The ranges for the uncertainties of the adsorption enthalpy were determined by assuming a shift of $\pm 1 \mathrm{~cm}$ of the deposition peak and a flow rate change of $\pm 5 \mathrm{ml} \mathrm{min}^{-1}$.

To help simulate wider deposition patterns a parameter change was introduced into the Monte Carlo simulation to address a continuous evaporation of iodine from the tellurium throughout the duration of the experiment. This is useful if significant ( $>5 \%$ ) activity remains in the sample after the experiment, suggesting an incomplete and continuous evaporation rather than a more discrete pulsed release. (a)

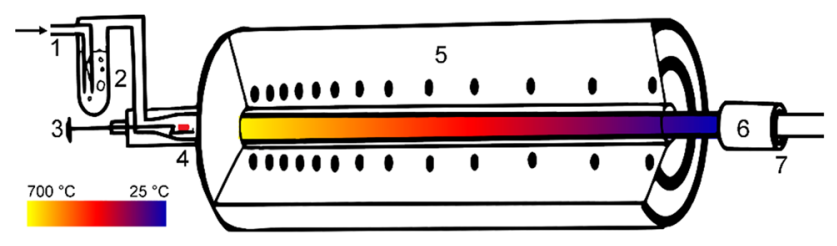

(b)

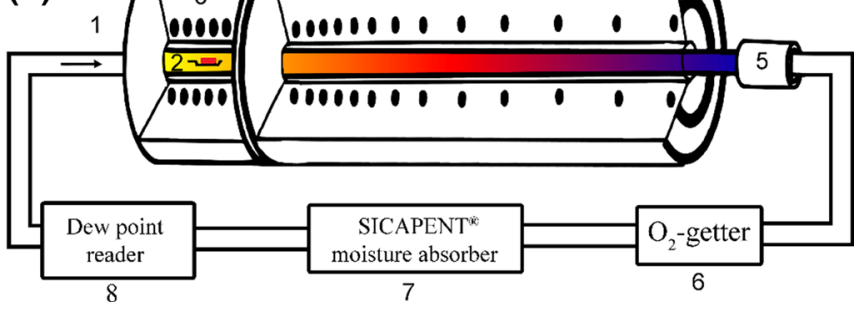

Furnace setup with loop for dry conditions, b featuring (1) Gas inlet, (2) Sample, (3) Starting furnace, (4) Gradient furnace, (5) Charcoal filter, (6) Oxygen getter. (7) SICAPENT® moisture absorber. (8) Dew point reader
Fig. 1 Sketch of the two experimental setups used, arrows showing the gas flow direction. Furnace setup for water saturated conditions a featuring (1) Gas inlet, (2) Water bubbler, (3) Sample pusher pin, (4) Sample, (5) Gradient furnace, (6) Charcoal filter, (7) Gas outlet. 


\section{Results and discussion}

In Table 1 we compile important experimental parameters and results of the experiments. Figures 2, 3 and 4 show the measured deposition patterns and temperatures, thermal gradients as well as outputs from Monte Carlo simulations with the corresponding extracted adsorption enthalpy.

\section{Helium carrier gas}

In experiments with helium carrier gas two different types of samples were used. For experiments I \& IV, a tellurium granule was used as the sample whereas for the remaining four experiments, pre-separated iodine from a silver foil was used instead. The purpose of studying samples with different tellurium content was to detect whether variations of the amount of tellurium in the system has an influence on the speciation of iodine. In all helium experiments except Exp. $\mathrm{VI}$, there is a recurring deposition pattern of two peaks being formed in close proximity to each other (Fig. 2).

The determined adsorption enthalpies of the two peaks are approximately -110 to $-120 \mathrm{~kJ} \mathrm{~mol}^{-1}$ and -90 to $-100 \mathrm{~kJ} \mathrm{~mol}^{-1}$ respectively. In dry conditions with an inert carrier gas, the dominant species should not contain elements other than iodine and tellurium. Because of the extremely low amounts of iodine present, the species considered in the following are $\mathrm{Te}_{2} \mathrm{I}$, TeI and monatomic I. The available data suggests a higher volatility for TeI compared to $\mathrm{Te}_{2} \mathrm{I}$ [7]. Based on a correlation determined for the adsorption of elements in carrier-free amounts on fused silica surfaces [9] a plausible assignment for the depositions with an adsorption enthalpy of about -90 to $-100 \mathrm{~kJ}$ $\mathrm{mol}^{-1}$ is monatomic iodine. The correlation from [9], modified to include a value determined in that work, relates the
Table 1 Experimental parameters and results of the performed experiments

\begin{tabular}{|c|c|c|c|c|c|c|}
\hline Exp & Gas & $\begin{array}{l}\mathrm{H}_{2} \mathrm{O} \text { in carrier } \\
\text { gas }(\text { vol-ppm) })^{\mathrm{b}}\end{array}$ & Dew point $\left({ }^{\circ} \mathrm{C}\right)$ & $\begin{array}{l}-\Delta H_{\mathrm{ads}} \\
\left(\mathrm{kJ} \mathrm{mol}^{-1}\right)\end{array}$ & $T_{\text {dep }}\left({ }^{\circ} \mathrm{C}\right)$ & Chemical speciation \\
\hline I & $\mathrm{He}$ & 12 & -59 & $\begin{array}{c}119 \pm 10 \\
98 \pm 10\end{array}$ & $\begin{array}{l}203 \\
104\end{array}$ & $\begin{array}{l}\mathrm{TeI} / \mathrm{Te}_{2} \mathrm{I} \\
\text { Monatomic I }\end{array}$ \\
\hline II (p) & $\mathrm{He}$ & 4 & -67 & $\begin{array}{c}143 \pm 10 \\
98 \pm 10\end{array}$ & $\begin{array}{l}317^{\mathrm{a}} \\
104\end{array}$ & $\begin{array}{l}\text { Transport of } \mathrm{TeI} / \mathrm{Te}_{2} \mathrm{I} ? \\
\text { Monatomic I }\end{array}$ \\
\hline III (p) & $\mathrm{He}$ & 0.1 & -90 & $\begin{array}{c}118 \pm 10 \\
99 \pm 10\end{array}$ & $\begin{array}{l}203 \\
104\end{array}$ & $\begin{array}{l}\mathrm{TeI} / \mathrm{Te}_{2} \mathrm{I} \\
\text { Monatomic I }\end{array}$ \\
\hline IV & $\mathrm{He}$ & $\sim 10,000$ & & $\begin{array}{l}97 \pm 5 \\
89 \pm 4\end{array}$ & $\begin{array}{l}95 \\
79\end{array}$ & $\begin{array}{l}\text { Monatomic I } \\
\text { iodine oxides/hydroxides }\end{array}$ \\
\hline $\mathrm{V}(\mathrm{p})$ & $\mathrm{He}$ & $\sim 10,000$ & & $\begin{array}{c}104 \pm 6 \\
89 \pm 5 \\
66 \pm 2\end{array}$ & $\begin{array}{l}146 \\
95 \\
24\end{array}$ & $\begin{array}{l}\mathrm{TeI} \mathrm{Te}_{2} \mathrm{I} \\
\text { Monatomic I } \\
\text { Iodine oxides/hydroxides }\end{array}$ \\
\hline VI (p) & $\mathrm{He}$ & $\sim 10,000$ & & $107 \pm 6$ & 178 & $\mathrm{TeI} / \mathrm{Te}_{2} \mathrm{I}$ \\
\hline VII & $\mathrm{H}_{2}$ & 55 & -47 & $95 \pm 10$ & 103 & Monatomic I \\
\hline VIII & $\mathrm{H}_{2}$ & 56 & -47 & $95 \pm 10$ & 103 & Monatomic I \\
\hline IX & $\mathrm{H}_{2}$ & $\sim 10,000$ & & $94 \pm 4$ & 112 & Monatomic I \\
\hline $\mathrm{X}$ & $\mathrm{H}_{2}$ & $\sim 10,000$ & & $96 \pm 4$ & 112 & Monatomic I \\
\hline XI & $\mathrm{O}_{2}$ & 0.2 & -86 & $\begin{array}{l}76 \pm 3 \\
67 \pm 2 \\
65 \pm 2\end{array}$ & $\begin{array}{l}55 \\
24 \\
24\end{array}$ & $\begin{array}{l}\text { Monatomic I } \\
\text { Iodine oxides/hydroxides } \\
\text { Iodine oxides/hydroxides }\end{array}$ \\
\hline XII & $\mathrm{O}_{2}$ & 1.1 & -76 & $\begin{array}{l}74 \pm 3 \\
65 \pm 2\end{array}$ & $\begin{array}{l}47 \\
24\end{array}$ & $\begin{array}{l}\text { Iodine oxides/hydroxides } \\
\text { Iodine oxides/hydroxides }\end{array}$ \\
\hline XIII & $\mathrm{O}_{2}$ & $\sim 10,000$ & & $\begin{array}{l}82 \pm 4 \\
67 \pm 2\end{array}$ & $\begin{array}{l}74 \\
30\end{array}$ & $\begin{array}{l}\text { Monatomic I } \\
\text { Iodine oxides/hydroxides }\end{array}$ \\
\hline XIV & $\mathrm{O}_{2}$ & $\sim 10,000$ & & $66 \pm 2$ & 28 & Iodine oxides/hydroxides \\
\hline
\end{tabular}

(p) indicates an experiment using pre-separated iodine as the sample. For each experiment the gas used, the dew point and the calculated water content is given, and for each observed chromatographic peak the deposition temperature $\left(T_{\mathrm{dep}}\right)$ and the deduced adsorption enthalpy $\left(-\Delta H_{\mathrm{ads}}\right)$ determined by MC-simulation are listed together with the presumed chemical speciation of the deposit

${ }^{a}$ Minor deposition

${ }^{\mathrm{b}} \mathrm{H}_{2} \mathrm{O}$ content calculated using the measured dew point and the calculator at http://www.michell.com/uk/ calculator/ 

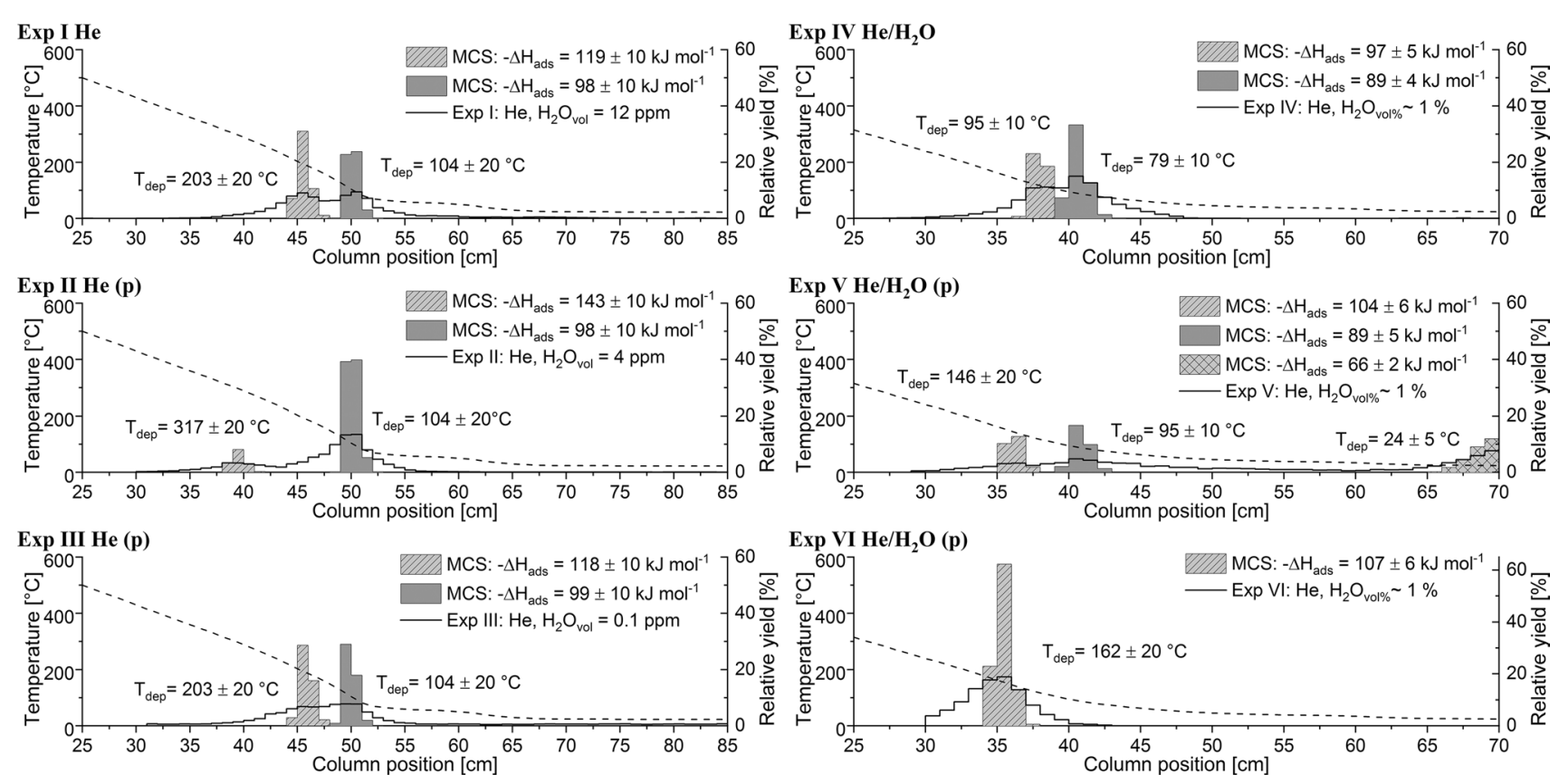

Fig. 2 Deposition patterns of experiments I-VI using helium as carrier gas (gas flow direction left to right; black dashed line: temperature gradient; solid black step line: measured deposition pattern; hatched histograms: output from the Monte Carlo simulation). Also

shown are deposition temperatures as well as extracted adsorption enthalpies for each peak. The experiments using pre-separated iodine evaporated from silver as starting material are labelled (p)
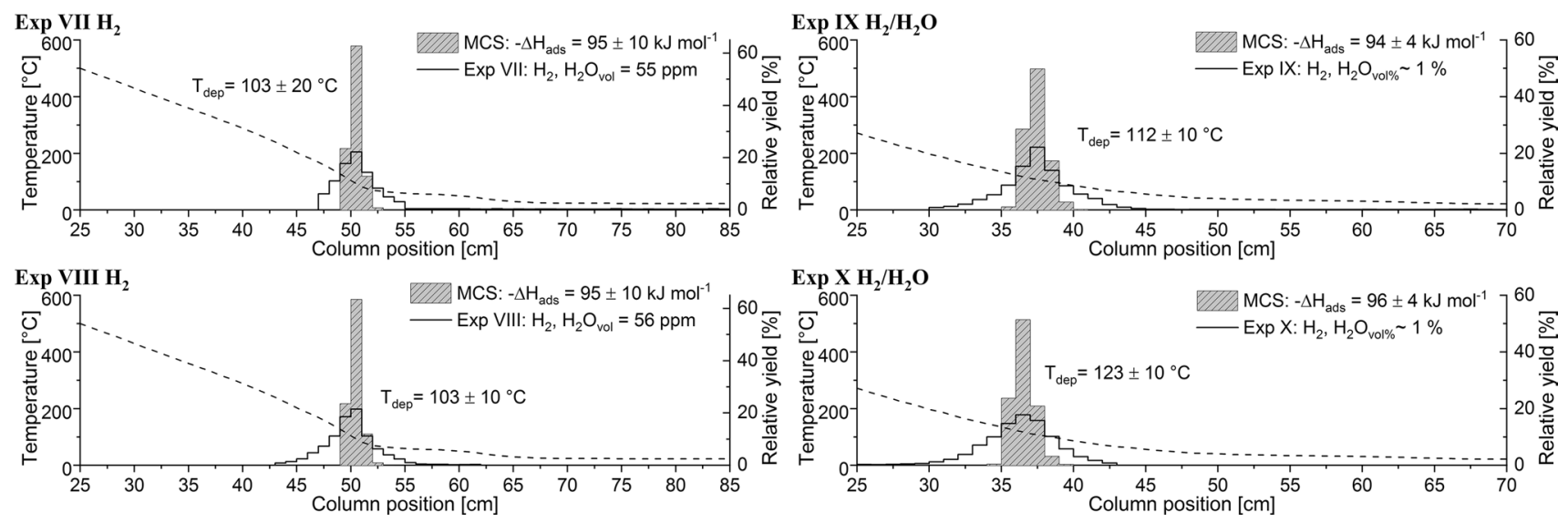

Fig. 3 Deposition patterns of experiments VII-X using hydrogen as carrier gas (gas flow direction left to right; black dashed line: temperature gradient; solid black step line: measured deposition pattern;

adsorption enthalpy on fused silica to the standard enthalpy of the monatomic gaseous element as

$-\Delta H_{\text {ads }}=(-3.7 \pm 8.6)+(0.85 \pm 0.06)-\Delta H_{\text {subl }}\left(\mathrm{kJ} \mathrm{mol}^{-1}\right)$

For monatomic iodine the standard enthalpy is equal to $107 \mathrm{~kJ} \mathrm{~mol}^{-1}$ [12]. Using the correlation this evaluates to an expected adsorption enthalpy of $-87 \pm 16 \mathrm{~kJ} / \mathrm{mol}$, overlapping with the experimentally determined value for the peaks

hatched histograms: output from the Monte Carlo simulation). Also shown are deposition temperatures as well as extracted adsorption enthalpies for each peak

with the lower deposition temperatures in the experiments performed in dry helium. The adsorption enthalpy value also agrees fairly well with a previous experimentally determined one for monatomic iodine on fused silica of $-92 \mathrm{~kJ} \mathrm{~mol}^{-1}$ [14]. Based on this assignment, we conclude that the depositions in the second peak at slightly higher temperatures most likely result from adsorption of TeI and/or $\mathrm{Te}_{2} \mathrm{I}$, possibly in variable relative amounts. One can observe a small reduction of the relative amount of Te-iodides compared to the amount 

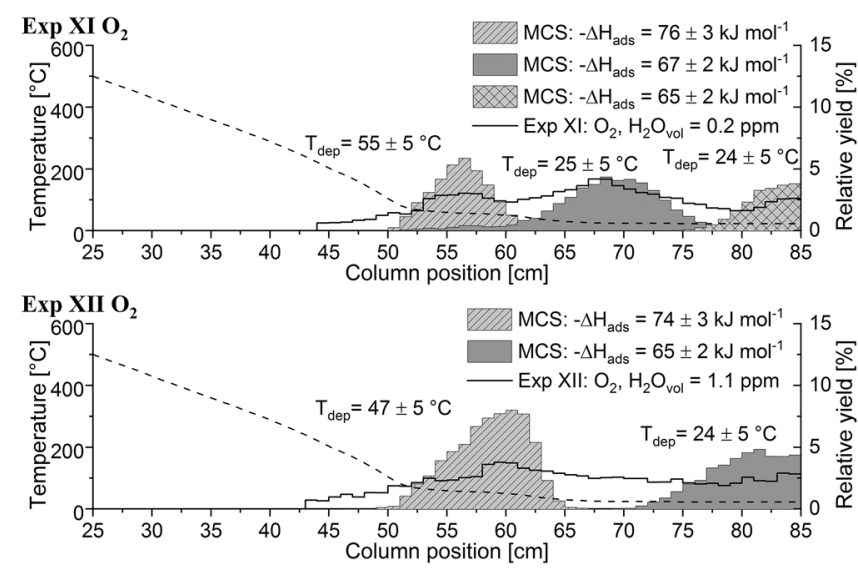

Fig. 4 Deposition patterns of experiments XI-XIV using oxygen as carrier gas (gas flow direction left to right; black dashed line: temperature gradient; solid black step line: measured deposition pattern; hatched histograms: output from the Monte Carlo simulation). Also shown are deposition temperatures as well as extracted adsorption

of elemental iodine in the two experiments performed using pre-separated iodine. However, still substantial amounts of iodine are deposited in the second peak, indicating that sufficient amounts of tellurium to form these species are carried over in the separation process. Considering the large excess of tellurium $\left(\sim 10^{10}\right)$ in the original sample this is not surprising. For Exp II using pre-separated iodine a minor high temperature deposition at $317{ }^{\circ} \mathrm{C}$ occurred. From the peak shape of the right-most deposition, one can infer that the $317{ }^{\circ} \mathrm{C}$ deposition appears to be part of a transport reaction possibly involving the species which makes up the $\sim 200{ }^{\circ} \mathrm{C}$ deposition in Exp I \& III, which is also supported by the observed peak broadening in comparison to the expected peak shape from the simulations. A similar behavior is also observed albeit at slightly different temperatures in Exp IV $\& \mathrm{~V}$. This indicates the chemical reactivity of the involved initially volatilized species and also suggests the superposition of chemical reactions with the multi-step adsorption processes, the full assessment of which is difficult not having at hand kinetic and thermodynamic data relevant for the chemical reactions. Therefore, the occurring species were treated equally as if they formed all directly upon volatilization from the source.

In moist conditions also reaction products of the above mentioned species with $\mathrm{H}_{2} \mathrm{O}$ could occur. However, the results obtained in moist helium carrier gas are rather similar to those obtained in dry helium. In the experiment using a tellurium granule as a sample the behavior aligned with that observed in the analog experiment at low moisture content. In one experiment under moist conditions (Exp. V) there was an additional low temperature peak formed analogous to the ones seen in oxygen (see section on oxygen carrier gas) indicating an ingress of trace oxygen during the experiment.
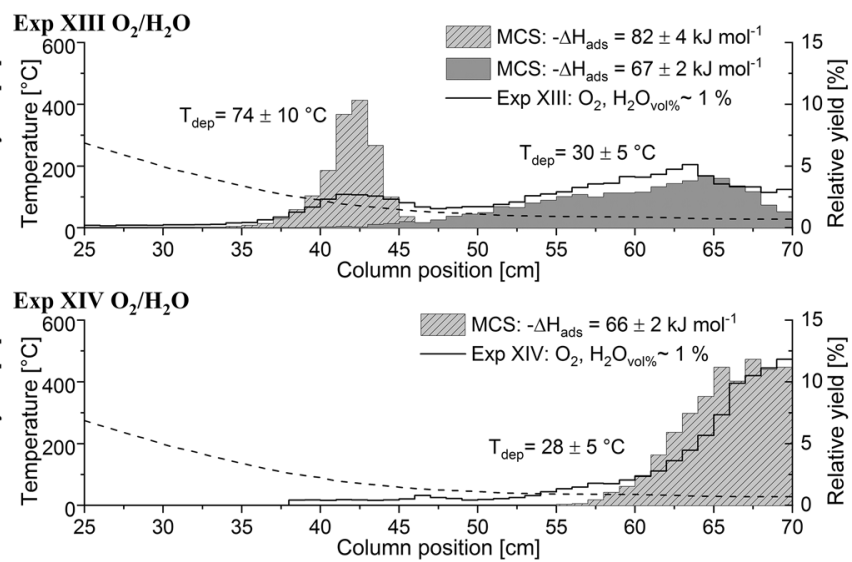

enthalpies for each peak. All peaks except for the right-most peak in the deposition pattern of Exp XI were fitted assuming continuous evaporation of iodine from the tellurium throughout the duration of the experiment

The formation of a broad single peak in Exp VI could be explained through close grouping of two peaks giving the illusion of a single deposition. It is located between where we find the depositions in dry carrier gas conditions using a tellurium granule sample. Overall, the deposition patterns found in moist atmosphere agree with the tentative identification of the main deposits as Te-iodides and monatomic iodine derived from the experiments in dry conditions. The similarities observed between experiments using samples with different iodine/tellurium ratios again indicate that the silver foil pre-separation method is not sufficient to reduce tellurium to low enough levels to prevent Te-iodide formation when using carrier free iodine.

\section{Hydrogen carrier gas}

In hydrogen as carrier gas only one peak is formed reproducibly at all conditions irrespective of moisture content (Fig. 3). Based on the argumentation outlined in the section above, the observed adsorption enthalpies indicate this species most likely is monatomic iodine. This requires that in hydrogen the tellurium iodides are decomposed according to the following two consecutive reactions:

$\mathrm{Te}_{2} \mathrm{I}+\mathrm{H}_{2} \rightleftarrows \mathrm{TeI}+\mathrm{H}_{2} \mathrm{Te}$

$\mathrm{TeI}+\mathrm{H}_{2} \rightleftarrows \mathrm{I}+\mathrm{H}_{2} \mathrm{Te}$

The hydrogen telluride formed in these reactions either is decomposed quickly at the conditions present inside the column, or is carried away due to its volatility [8]. Thus, the equilibria (2) and (3) would be driven towards the formation of iodine. 
From chemical reasoning there is a possibility of a third reaction occurring, producing $\mathrm{HI}$ from the monatomic iodine. Formation of HI would invariably result in a clear large deposition in the charcoal filter owing to the volatility of the species as it is a gas at room temperature [8]. No such increase is observed, only a small variation within the uncertainty of the $\gamma$-measurement of the filter, indicating that this reaction does not take place under the conditions prevailing in the present experiments.

At moisture saturated conditions in hydrogen no significant change is observed other than a slight broadening of the peaks. This is however also present in the Monte Carlo simulation and therefore likely just an effect of the properties of the gradient in that furnace.

\section{Oxygen carrier gas}

In oxidizing conditions, the chemistry of the system changes dramatically, with multiple species occurring that have lower affinities to the silica surface compared to those observed in helium and hydrogen. In some of the experiments, this led to a partial transport of iodine to the charcoal filter located at the exit of the thermochromatography column. The speciation seems unstable with the number of pronounced peaks fluctuating, as well as the shape of the peaks themselves (Fig. 4). Successfully reproducing the peaks using Monte Carlo simulation was not possible for all of them, suggesting processes are occurring that have not yet been implemented in the code. Such processes include for example in-flight speciation changes in regions where the adsorption time is non-negligible, resulting in an unpredictable adsorption behavior.

Possible speciations in these conditions include different iodine oxides as well as HIO and additional oxo-acids of iodine $\left(\mathrm{HIO}_{\mathrm{x}}\right)$. These are likely produced through the oxidation of the $\mathrm{TeI} / \mathrm{Te}_{2} \mathrm{I}$ while in parallel tellurium oxide is formed. The multiple products formed in such reactions may be very sensitive to local conditions. Variations in these conditions could result from small fluctuations in temperature driven by the very flat temperature gradient as well as changes in $\mathrm{H}_{2} \mathrm{O}$ content of the gas. Testing of the influence of different water levels in the bubbler described in the "Experimental" section confirmed that this introduces a maximum variability of $\pm 2000 \mathrm{ppm}$ in $\mathrm{H}_{2} \mathrm{O}$ concentration in the bulk flow.

The evaporation of iodine was quantified for one experiment with each carrier gas, with complete evaporation observed in reducing and inert conditions, whereas oxidizing conditions induced retention in the tellurium matrix. To account for this retention and its effect on the observed deposition patterns, the continuous evaporation of iodine from the tellurium throughout the duration of the experiment was modeled in the Monte Carlo simulation as explained above.
This was sufficient to successfully simulate the shapes of some of the broad peaks, but as mentioned before there are other chemical reaction phenomena at play, which the used modelling and simulation algorithm does not fully describe. In Exp XI, the right-most peak in the deposition pattern could not be simulated using the described method despite it being an oxygen carrier gas experiment. This peak shape could only be reproduced assuming instantaneous release, suggesting that the evaporation of iodine from tellurium in oxygen has a faster evaporating fraction combined with one that has higher retention. Simulating a peak with a maximum at low temperature using a delayed release results in a peak much wider than the one present in the measured deposition pattern. We stress that one must remember that this method is not perfect as is evident from some experiments where a good fit of simulation to result was not possible (Exp XII for example). This suggests that there are additional processes going on such as transport reactions in the region of lasting adsorption, which influence the result [15]. To obtain more precise results on the behavior of these very volatile species, extending the temperature gradient to temperatures below room temperature is required. This would potentially capture species that were found in the charcoal filter. Additionally, it would steepen the gradient around room temperature leading to sharper deposition peaks and thus facilitating their evaluation.

\section{Conclusions}

The adsorption behavior of iodine on a fused silica surface when evaporated from a tellurium matrix has been successfully studied. In water saturated and dry conditions in helium, hydrogen, and oxygen it was possible to extract adsorption properties for the evaporated iodine. In inert conditions there was a recurring formation of two peaks. While the peak with the higher absolute adsorption enthalpy appears to fluctuate slightly between $-100 \mathrm{~kJ} \mathrm{~mol}^{-1}$ and almost $-120 \mathrm{~kJ} \mathrm{~mol}^{-1}$ (with one presumed transport peak present around $-140 \mathrm{~kJ} \mathrm{~mol}^{-1}$ ), the lower has an adsorption enthalpy of about -90 to $-100 \mathrm{~kJ} \mathrm{~mol}^{-1}$. A pre-separation of iodine from the irradiated tellurium appears to have no consistent effect on the speciation. The peak with an adsorption enthalpy of approximately $-90 \mathrm{~kJ} \mathrm{~mol}^{-1} \mathrm{can}$ be assigned to monatomic iodine based on an empirical correlation for element adsorption to fused silica as well as a previously experimentally determined value for monatomic iodine adsorption on fused silica. The peaks with the higher absolute values of adsorption enthalpies are assumed to result from deposition of tellurium iodides ( $\mathrm{TeI}$ or $\left.\mathrm{Te}_{2} \mathrm{I}\right)$. Based on the deposition patterns observed under the different conditions it would appear that any tellurium iodides only survive in helium carrier gas, both in dry and in moist 
conditions. For reducing conditions, consistently a single species adsorbing with $\Delta H_{\text {ads }}=-95 \pm 5-10 \mathrm{~kJ} \mathrm{~mol}^{-1}$ is observed, regardless of the water content of the carrier gas. This indicates that the tellurium iodides observed in helium carrier gas are decomposed in hydrogen. The absence of iodine in the charcoal filter suggests that the reaction does not progress to $\mathrm{HI}$ which would likely be very volatile and not stick to the column at all. In dry and moist oxygen a variety of species with even higher volatility than monatomic iodine are observed. These species most likely are iodine oxides and oxoacids of iodine whose relative abundance is strongly influenced by small fluctuations in the temperature gradient and moisture content. Overall, the results presented here give valuable information on the iodine containing species that can form when neutron irradiated tellurium is heated in different chemical conditions. These results should prove useful when interpreting results from similar experiments performed using tellurium doped LBE samples prepared in order to study iodine released from the liquid metal coolant of an ADS and its deposition.

Author contributions EK: Conceptualization, Methodology, Software, Validation, Formal analysis, Investigation, Writing-Original Draft, Visualization. JN: Conceptualization, Validation, Data Curation, Writing-Review \& Editing, Visualization, Supervision, Project administration, Funding acquisition. RE: Validation, Methodology, Software, Writing-Review \& Editing, Visualization. AV: Methodology, Resources. AT: Validation, Writing—Review \& Editing, Supervision.

Funding This work was funded by the Project MYRTE under EURATOM HORIZON2020 Grant Agreement No. 662186. Open Access funding provided by Lib4RI - Library for the Research Institutes within the ETH Domain: Eawag, Empa, PSI \& WSL.

\section{Compliance with ethical standards}

Conflict of interest The authors declare that they have no conflict of interest.

Open Access This article is licensed under a Creative Commons Attribution 4.0 International License, which permits use, sharing, adaptation, distribution and reproduction in any medium or format, as long as you give appropriate credit to the original author(s) and the source, provide a link to the Creative Commons licence, and indicate if changes were made. The images or other third party material in this article are included in the article's Creative Commons licence, unless indicated otherwise in a credit line to the material. If material is not included in the article's Creative Commons licence and your intended use is not permitted by statutory regulation or exceeds the permitted use, you will need to obtain permission directly from the copyright holder. To view a copy of this licence, visit http://creativecommons.org/licenses/by/4.0/.

\section{References}

1. Aït Abderrahim H, Baeten P, De Bruyn D, Heyse J, Schuurmans P, Wagemans J (2010) MYRRHA, a Multipurpose hYbrid Research Reactor for High-end Applications. Nucl Phys News. https://doi. org/10.1080/10506890903178913

2. Neuhausen J, Eichler B (2009) Investigations on the thermal release of iodine from liquid eutectic lead-bismuth alloy. Radiochim Acta. https://doi.org/10.1524/ract.2006.94.5.239

3. Rijpstra K, Neuhausen J, Espegren F, Retegan T (2015) Interaction between iodineand liquid lead bismuth. Deliverable D4.4 of the EU FP7 SEARCH project

4. Ait Abderrahim H, Sobolev V, Malambu E (2005) Fuel design for the experimental ADS MYRRHA. Technical Meeting on use of LEU in ADS, 10-12 Oct 2005. IAEA, Vienna, Austria

5. Zvara I (2008) The inorganicchemistry of heavy elements, 1st edn. Springer, Dordrecht

6. Maugeri EA, Neuhausen J, Eichler R, Piguet D, Schumann D (2014) Thermochromatography study of volatile tellurium species in various gas atmospheres. J Nucl Mater. https://doi. org/10.1016/j.jnucmat.2014.04.036

7. Kniep R, Rabenau A (1983) Physical and inorganic chemistry. Topics in current chemistry, vol 111. Springer, Berlin

8. Wiberg N, Holleman AF (2007) Lehrbuch der Anorganischen Chemie, 102nd edn. De Gruyter, Berlin

9. Steinegger P, Asai M, Dressler R, Eichler R, Kaneya Y, Mitsukai A, Nagame Y, Piguet D, Sato TK, Schädel M, Takeda S, Toyoshima A, Tsukada K, Türler A, Vascon A (2016) Vacuum chromatography of $\mathrm{Tl}$ on $\mathrm{SiO}_{2}$ at the single-atom level. J Phys Chem C. https://doi.org/10.1021/acs.jpcc.5b12033

10. Bächmann K, Matschoss V (1975) Separation of nuclear reaction products in the gas phase-I: separation of Tc in a flow of oxygen. J Inorg Nucl Chem. https://doi.org/10.1016/0022-1902(75)80116 $-3$

11. Nucleonica GmbH (2019) Nuclide datasheets. Nucleonica Nuclear Science Portal (www.nucleonica.com), Version 3.0.151.0001, Karlsruhe, Germany

12. Barin I (1995) Thermochemical data of pure substances, 3rd edn Wiley-VCH, Weinheim

13. Eichler B, Domanov VP (1975) Verflüchtigung von Radionukliden im Luftstrom und ihre Abscheidung im Temperaturgradientrohr. J Radioanal Chem. https://doi.org/10.1007/BF02516873

14. Eichler B, Zude F, Fan W, Trautmann N, Hermann G (1992) Volatilization and deposition of ruthenium oxides in a temperature gradient tube. Radiochim Acta. https://doi.org/10.1524/ ract.1992.56.3.133

15. Schäfer H (1962) Chemische Transportreaktionen: der Transport anorganischer Stoffe über die Gasphase und seine Anwendungen. Wiley-VCH Verlag GmbH \& Co., Weinheim 